\title{
Comparative study of clomiphene citrate versus letrozole as first-line ovulation induction drug in infertile polycystic ovary syndrome women
}

\author{
Mahija Sahu ${ }^{1 *}$, Nihar Ranjan Rout ${ }^{2}$
}

\begin{abstract}
${ }^{1}$ Department of Obstetrics and Gynecology, Sriram Chandra Bhanj Medical College and Hospital, Cuttack, Odisha, India

${ }^{2}$ Department of Obstetrics and Gynecology, Institute of Medical Sciences and SUM Hospital, Bhubaneswar, Odisha, India
\end{abstract}

Received: 22 January 2020

Revised: 20 February 2020

Accepted: 28 February 2020

\section{*Correspondence:}

Dr. Mahija Sahu,

E-mail: mahija_sahu@yahoo.co.in

Copyright: (C) the author(s), publisher and licensee Medip Academy. This is an open-access article distributed under the terms of the Creative Commons Attribution Non-Commercial License, which permits unrestricted non-commercial use, distribution, and reproduction in any medium, provided the original work is properly cited.

\begin{abstract}
Background: Polycystic ovary syndrome is the commonest endocrinopathy resulting in anovulatory infertile young women. Clomifene citrate (clomiphene) is a long-standing standard drug for ovulation induction, and is still considered as first line option in PCOS women. However, clomiphene has certain disadvantage letrozole an aromatase inhibitor acts by reducing estrogen production and has no adverse effects on endometrium and cervical mucous. Indian PCOS women have high prevalence of insulin resistance and thus are likely to have high clomiphene resistance. So letrozole could prove to be a good alternative for ovulation induction in such women.

Methods: This was a prospective randomized, parallel, comparative clinical trial of two ovulation induction drugs letrozole $5 \mathrm{mg}$ versus clomiphene citrate $100 \mathrm{mg}$ as first-line ovulation induction drug in infertile polycystic ovarian syndrome women. The target population of the study was one hundred infertile women with PCO (taking at least 2 Rotterdam's parameters). 50 women were allocated to clomifene citrate and 50 were allocated to Letrozole for ovulation induction. Parameters like age, duration of infertility, B MI, ovulation rate, number of follicles, pregnancy rate, endometrial thickness were noted and analyzed.

Results: In letrozole group, the ovulation rate, mono-follicular development, mean endometrial thickness and pregnancy rate was better in comparison to clomifene citrate group.

Conclusions: The result of this study suggests that letrozole may replace clomiphene as the first line drug for ovulation induction in infertile PCOS women.
\end{abstract}

Keywords: Clomifene citrate, Letrozole, Ovulation induction, Polycystic ovary syndrome

\section{INTRODUCTION}

Polycystic ovary syndrome, an entity described by Irving F. Stein and Michael L. Leventhal in 1953 for the first time. ${ }^{1}$ With the advent of sophisticated diagnostic modalities coupled with continued research many new concepts of this syndrome has been highlighted. Polycystic ovary syndrome (PCOS) is the commonest endocrinopathy resulting in anovulatory infertility in young women. ${ }^{2}$
There are many clinical manifestations of the syndrome, and infertility due to chronic anovulation is one of the commonest. Clomiphene citrate is a long-standing, standard drug for ovulation induction and is still considered as first-line option in PCOS women for more than 40 years. $^{3}$

However, clomiphene has certain well-defined disadvantages. Treatment with clomiphene is associated with discrepancy in ovulation and pregnancy rates. 
Miscarriage rate is higher than general population and 20$25 \%$ PCOS women are resistant to clomiphene. Antiestrogenic effect of clomiphene leads to prolonged depletion of estrogen receptors, adversely affecting endometrial growth and development as well as quantity and quality of cervical mucus. ${ }^{4}$ Letrozole is an orallyactive aromatase inhibitor, with good potential for ovulation induction.

Letrozole acts by reducing estrogen production by blocking androgens to estrogen conversion. Additionally, it has no adverse effect on endometrium and cervical mucus. In India, letrozole was approved for ovulation induction from 2006 to 2011 by the drug controller general of India (DCGI). Letrozole has been shown to have good ovulation rate in clomiphene-resistant PCOS women.

\section{METHODS}

The present study is a prospective, randomized, parallel, comparative clinical trial which was approved by institutional ethics committee, SCB Medical College, Cuttack, Odisha, India.

The target population of the study was one hundred infertile women with PCO (taking at least 2 Rotterdam's parameters 5 between ages of 21-35 years attending gynecology OPD between January 2017 to September 2018. All the patients enrolled in this study were subjected to thorough clinical examination, biochemical investigation, ultrasonography, tests for tubal patency and husband's semen parameter.

Exclusion criteria of this study were women with uterine/ adnexal pathology (Eg) fibroid, ovarian cyst is excluded from the study. Women with clinical features of hyperthyroidism, hypothyroidism are excluded. Those with previous history of any surgeries related to genital tract as per history were excluded. Those with impaired hepatic/renal function were excluded. Lack of willingness.

\section{Clinical examination}

- The patients enrolled in this study were subjected to clinical examination which included

- All patients' height and weight were measured. BMI was then calculated. BMI = weight in $\mathrm{kg} / \mathrm{hight}$ in $\mathrm{m}^{2}$. It is a reliable indicator, inexpensive and easy to perform

- Clinical evidence of acne, hirsutism, acanthosis nigricans, hyper thyroidism and hypothyroidism were looked for in all patients enrolled in this study.

\section{Biochemical investigations}

Complete blood count, random blood sugar, renal function test and liver function test done in all patients.
Any abnormalities in any one of these investigations, those patients were excluded from this study.

For bilateral tubal patency - hysterosalpingography (HSG) was performed. Those with abnormal tubal patency were excluded from this study.

\section{Ultrasonography}

All patients underwent transvaginal ultrasonography using 2.5 MHz probe of GE Healthcare Voluson S8 BT12 ultrasound machine of obstetrics and gynecology department, SCB Medical College, Cuttack, Odisha, India.

All patients had antral follicle count of at least 10 with size $2-9 \mathrm{~mm}$.

The ovarian volume $=/>10 \mathrm{ml}$. Evidence of fibroid and ovarian cyst/ adnexal masses ruled out.

The selected randomized patients were allocated as group letrozole and group clomiphene, of which group letrozole patients were administered letrozole $5 \mathrm{mg}$ OD from D2D6 of the menstrual cycle and group clomiphene patients were administered clomiphene citrate $100 \mathrm{mg}$ OD from D2-D6 of the menstrual cycle.

Both the group of patients was subjected to transvaginal ultrasonographic monitoring of number of follicles and endometrial thickness from D10 onwards.

The treatment was discontinued in both the groups, if patients, developed ovarian enlargement or hyper stimulation.

The number of follicles, ovulation rate, endometrial thickness and pregnancy rate were compared in the two groups.

A group test or the student-t test was used to compare data as appropriate.

\section{Statistical analysis}

A $p$ value $<0.05$ was considered to be statistically significant.

\section{RESULTS}

The mean duration of infertility in group letrozole is 2.89 years and in group clomiphene is 2.93 years with $p$ value is $0.819(>0.05)$. Which is not significant. Both the groups are comparable with respect to mean duration of infertility (Table 1).

The mean body mass index in group letrozole is 26.20 with SD of 2.0628. The mean body mass index in Group clomiphene is 26.09 with SD of 2.1366. Both the groups 
are comparable with respect to body mass index with $\mathrm{p}$ value 0.809 (>0.05) not significant (Table 2).

The ovulation response group tabulation shows that out of 50 patients in letrozole group 38 patients ovulated accounting to $76 \%$. Out of 50 patients in clomiphene group 26 patients ovulated accounting to $52 \%$. By applying chi-square tests, chi-square value is 6.250 and $\mathrm{p}$ value is $0.012 * .(<0.05)$ which is significant. This shows that there is statistically significant difference in ovulation induction rate between the group of patients treated with letrozole and clomiphene. Letrozole treated patients had better ovulation rates than clomiphene (Table 3).

Table 1: Mean duration of infertility independent samples test group statistics.

\begin{tabular}{|lllll|l|}
\hline Study group & $\mathbf{N}$ & Mean & SD & Std. error mean & p value \\
\hline Letrozole & 50 & 2.89 & 0.84086 & 0.11892 & \\
\cline { 1 - 4 } Clomiphene & 50 & 2.93 & 0.8979 & 0.12698 & $\mathrm{p}=0.819$ \\
\hline
\end{tabular}

Table 2: BMI group statistics.

\begin{tabular}{|lllll|l|}
\hline Study group & $\mathbf{N}$ & Mean & SD & Std. error mean & p value \\
\hline Letrozole & 50 & 26.2 & 2.06289 & 0.29174 & \multirow{2}{*}{0.801} \\
\hline Clomiphene & 50 & 26.094 & 2.1366 & 0.30216 & $\mathrm{p}=0.801$ \\
\hline
\end{tabular}

Table 3: Ovulation statistics.

\begin{tabular}{|c|c|c|c|c|c|}
\hline \multirow{2}{*}{ Ovulation } & \multicolumn{2}{|l|}{ Letrozole } & \multicolumn{2}{|l|}{ Clomiphene } & \multirow{2}{*}{ p value } \\
\hline & No. of cases & Percentage & No. of cases & Percentage & \\
\hline Oclomipheneured & 38 & $76 \%$ & 26 & $52 \%$ & \multirow{3}{*}{$\mathrm{p}=0.012$} \\
\hline Not oclomipheneured & 12 & $24 \%$ & 24 & $48 \%$ & \\
\hline Total & 50 & $100 \%$ & 50 & $100 \%$ & \\
\hline
\end{tabular}

$\mathrm{p}$ value is $0.012 *$.

Table 4: Comparison of number of follicle statics.

\begin{tabular}{|llll|}
\hline & Letrozole & Clomiphene & P value \\
\hline Mono follicular & $81.25 \%$ & $32.65 \%$ & $\mathrm{P}=0.000$ \\
\hline Multi follicular & $18.75 \%$ & $67.34 \%$ & $\chi^{2}=23.66$ \\
\hline
\end{tabular}

Table 5: Endometrial thickness.

\begin{tabular}{|llllll|}
\hline Study group & $\mathbf{N}$ & Mean & SD & Std. error mean & p value \\
\hline Letrozole & 50 & 8.298 & 0.7836 & 0.1108 & $\mathrm{p}=0.00$ \\
\hline Clomiphene & 50 & 7.18 & 0.7259 & 0.1026 & $\mathrm{p}$ \\
\hline
\end{tabular}

$\mathrm{p}$ value obtained is $0.000 *(<0.05)=$ highly significant.

Table 6: Pregnancy rate.

\begin{tabular}{|c|c|c|c|c|c|}
\hline \multirow{2}{*}{ Pregnancy } & \multicolumn{2}{|l|}{ Letrozole } & \multicolumn{2}{|l|}{ Clomiphene } & \multirow{2}{*}{ p value } \\
\hline & No. of cases & Percentage & No. of cases & Percentage & \\
\hline Oclomipheneured & 12 & $24 \%$ & 6 & $12 \%$ & \multirow{3}{*}{$\mathrm{p}=0.118$} \\
\hline Not oclomipheneured & 38 & $76 \%$ & 44 & $88 \%$ & \\
\hline Total & 50 & $100 \%$ & 50 & $100 \%$ & \\
\hline
\end{tabular}

The cross tabulation shows that in letrozole group, $81.25 \%$ of the cases developed single follicle and $18.75 \%$ of the cases developed multiple follicles with letrozole. In clomiphene group, $32.65 \%$ of the cases developed single follicle and $67.34 \%$ of the cases developed multiple follicles. By applying the chi-square tests, chi-square value is 23.66 and $\mathrm{p}$ value $=0.000^{*}(<0.05)$ which is highly significant. Letrozole treated cases had better 
mono-follicular ovulation rates as compared to clomiphene treated group (Table 4).

Table 5 shows the mean endometrial thickness in letrozole group is $8.29 \mathrm{~mm}$ with a SD of 0.7836 . In clomiphene group the mean endometrial thickness is 7.18 $\mathrm{mm}$ with a SD of $0.7259 \mathrm{p}$ value obtained is $0.000 *$ $(<0.05)=$ highly significant $($ Table 5$)$.

The pregnancy group tabulation shows that in letrozole group, 24\% of cases pregnancy occurred and in clomiphene group $12 \%$ of cases pregnancy occurred. By applying chi-square tests $\mathrm{p}$ value 0.118 . (>0.05) was not significant. This shows that letrozole treated patients had better ovulation rates than clomiphene but it was not statistically significant (Table 6).

\section{DISCUSSION}

Clomiphene citrate (clomiphene) has been used for ovulation induction since 1960s. It is still considered first-line drug for anovulatory PCOS women. However, clomiphene resistance (15-20\%), endometrial thinning, and poor cervical mucus (15-50\% of cases) makes it less effective in many situations. 72-76 letrozole, which is an aromatase inhibitor, has been explored as a good alternative by many researchers, but the evidence about its efficacy as compared to clomiphene is conflicting.

The present study showed better ovulation rates in group with letrozole as evidenced by $76 \%$ ovulation achieved in this group compared to $52 \%$ in clomiphene group which were comparable with studies conducted by Atay et al, and Begum et al. ${ }^{6}$ In the present study the ovulation rate in letrozole group was more and statistically highly significant $(\mathrm{p}<0.012)$ as compared to clomiphene group. Similar result was reported by Begum et al, (letrozole $62.55 \%$, clomiphene $37.5 \%, \mathrm{p}<0.05$ ), Atay et al (letrozole $82.4 \%$, Clomiphene 63.6\%, p=0.016), Dehbasi et al, (letrozole $60 \%$, clomiphene $32 \%, \mathrm{p}=0.009$ ). But few studies like Bayer et al, Kar S found no statistically significant for ovulation rate between letrozole and clomiphene group. ${ }^{7}$ This may be explained by the fact that letrozole creates an estrogen deficient environment by inhibiting conversion of androgens to estrogens. This releases the pituitary from negative feedback of estrogens and releases FSH. Also, an added positive effect is increased follicular sensitivity to FSH receptor gene expression 79-82. Multi-follicular development was statistically significantly higher in clomiphene group in this study (clomiphene $67.34 \%$, let $18.75 \%, \mathrm{p}=0.00$ ). This is expected and corroborated by number of studies. 83-85 like Biljan and colleagues. Letrozole resulted in monofolliculogenesis in $81.25 \%$ of cases, which is optimal for ovulation induction in PCOS women.

However, where multiple follicular development is needed, letrozole may be inadequate alone. This is because aromatase inhibitors do not deplete estrogen receptors, as does clomiphene, normal central feedback mechanisms remain intact. As the dominant follicle grows and estrogen levels rise, normal negative feedback occurs centrally, resulting in suppression of FSH and atresia of the smaller growing follicles. A single dominant follicle, and mono-ovulation, should occur in most cases. ${ }^{8}$

This is in direct contrast with clomiphene which leads to in higher estrogen level thereby resulting in increased number of follicles. ${ }^{9}$

Endometrial thickness is the maximal thickness of the endometrial lining in the plane through the central longitudinal axis of the uterine body. In the present study mean endometrial thickness was more in letrozole group $(8.29 \pm 0.78 \mathrm{~mm})$ as compared to clomiphene group $(7.18 \pm 0.72 \mathrm{~mm})$ and this was very highly significant $(\mathrm{p}<0.001)$. Mitwally and Casper found letrozole associated with greater endometrial thickness. ${ }^{10}$ The similar pattern is seen in most of other studies apart from Al Fozan et al, which demonstrates the reverse. ${ }^{11}$

The above results consolidate the belief that endometrium is one of the most important targets of the antiestrogenic effect of clomiphene and may explain a large part of the lower pregnancy rate and possible higher miscarriage rate with clomiphene.

A reduction in endometrial thickness below the required level for implantation was found in up to $30 \%$ of women receiving clomiphene according to Gonen et al. This could be due to prolonged estrogen receptor depletion in the endometrium. ${ }^{12}$

In this study, pregnancy rate achieved after ovarian stimulation was $24 \%$ in Letrozole and $12 \%$ in clomiphene with $\mathrm{p}=0.118$ i.e. statistically not significant. But almost two-fold increase in pregnancy rate was observed in patients who received letrozole. Badawy et al, with 438 women reported slightly better pregnancy rate in clomiphene group $(15.1 \%$ in letrozole and $17.9 \%$ in $\mathrm{CC}$ group, $\mathrm{p}=0.72){ }^{13}$

Bayer et al, with 74 women, Zeinalzaden et al, with 107 women, both reported slightly better pregnancy rates with letrozole; however, no statistically significant difference between the two groups. ${ }^{14}$

Funding: No funding sources

Conflict of interest: None declared

Ethical approval: The study was approved by the Institutional Ethics Committee

\section{REFERENCES}

1. Stein IF, Leventhal ML. Amenorrhea associated with bilateral polycystic ovaries. Am J Obstet Gynecol. 1935;29:181-91.

2. The Australian Longitudinal Study on Women's Health (ALSWH), 2017. Available at: 
https://www.alswh.org.au/publications - andreports/published - papers. Accessed on $19^{\text {th }}$ July 2017.

3. Greenblatt RB, Barfield WE, Jungck EC, Ray AW. Induction of ovulation with MRL/41. JAMA. 1961;178:101-5.

4. Biljan MM, Mahutte NG, Tulandi T, Tan SL. Prospective randomized double-blind trial of the correlation between time of administration and antiestrogenic effects of clomiphene citrate on reproductive end organs. Fertil Steril. 1999;71(4):633-8.

5. The Rotterdam ESHRE/ASRM sponsored PCOS con-sensus workshop group. Revised 2003 consensus on diagnostic criteria and long-term health risks related to polycystic ovary syndrome (PCOS). Human Reprod. 2004;19:41-7.

6. Atay VC, Muhcu M, Cam M, Karateke A. Comparison of letrozole and clomiphene citrate in women with polycystic ovaries undergoing ovarian stimulation. J Int Med Res. 2006;34:73-6.

7. Kar S. Clomiphene citrate or letrozole as first-line ovulation induction drug in infertile PCOS women: a prospective randomized trial. J Hum Reprod Sci. 2012;5(3):262-5.

8. Sioufi A, Gauducheau N, Pineau V, Marfil F, Jaouen A, Cardot JM, et al. Absolute bioavailability of letrozole in healthy postmenopausal women. Biopharmac Drug Dispos. 1997;18(9):779-89.

9. Kerin JF, Liu JH, Phillipou G, Yen SSS. Evidence for a hypothalamic site of action of clomiphene citrate in women. J Clin Endocrinol Metab. 1985;61:265-8.

10. Mitwally MFM, Casper RF. Aromatase Inhibitors: a novel method of ovulation induction in women with polycystic ovarian syndrome. Reprod Technol. 2000;10:244-7.

11. Al-Fozan H, Al-Khadouri M, Tan SL, Tulandi T. A randomized trial of letrozole versus clomiphene citrate in women undergoing superovulation. Fertil Steril. 2004;82:1561-3.

12. Gonen Y, Casper RF. Sonographic determination of an adverse effect of clomiphene citrate on endometrial growth. Hum Reprod. 1990;5:670-4.

13. Badawy A, Mosbah A, Shady M. Anastrozole or letrozole for ovulatin induction in clomipheneresistant women with polycystic ovarian syndrome: a prospective randomize trial. Fertil Steril. 2008;89:1209-12.

14. Abu Hashim H, Shokeir T, Badawy A. Letrozole versus combined metformin and clomiphene citrate for ovulation induction in clomiphene- resistant women with polycystic ovary syndrome: A randomized controlled trial. Fertile Steril. 2010;94:1405-9.

Cite this article as: Sahu M, Rout NR. Comparative study of clomiphene citrate versus letrozole as firstline ovulation induction drug in infertile polycystic ovary syndrome women. Int J Reprod Contracept Obstet Gynecol 2020;9:2948-52. 